\title{
Natural Competence Rates Are Variable Among Xylella fastidiosa Strains and Homologous Recombination Occurs In Vitro Between Subspecies fastidiosa and multiplex
}

\author{
Prem P. Kandel, ${ }^{1}$ Rodrigo P. P. Almeida, ${ }^{2}$ Paul A. Cobine, ${ }^{3}$ and Leonardo De La Fuente ${ }^{1}$ \\ ${ }^{1}$ Department of Entomology and Plant Pathology, Auburn University, Auburn, AL, U.S.A.; ${ }^{2}$ Department of Environmental \\ Science, Policy and Management, University of California, Berkeley, CA, U.S.A.; and ${ }^{3}$ Department of Biological Sciences, \\ Auburn University \\ Accepted 19 April 2017.
}

\begin{abstract}
Xylella fastidiosa, an etiological agent of emerging crop diseases around the world, is naturally competent for the uptake of DNA from the environment that is incorporated into its genome by homologous recombination. Homologous recombination between subspecies of $X$. fastidiosa was inferred by in silico studies and was hypothesized to cause disease emergence. However, no experimental data are available on the degree to which $X$. fastidiosa strains are capable of competence and whether recombination can be experimentally demonstrated between subspecies. Here, using $X$. fastidiosa strains from different subspecies, natural competence in 11 of 13 strains was confirmed with plasmids containing antibiotic markers flanked by homologous regions and, in three of five strains, with dead bacterial cells used as source of donor DNA. Recombination frequency differed among strains and was correlated to growth rate and twitching motility. Moreover, intersubspecific recombination occurred readily between strains of subsp. fastidiosa and multiplex, as demonstrated by movement of antibiotic resistance and green fluorescent protein from donor to recipient cells and confirmed by DNA sequencing of the flanking arms of recombinant strains. Results demonstrate that natural competence is widespread among $X$. fastidiosa strains and could have an impact in pathogen adaptation and disease development.
\end{abstract}

Xylella fastidiosa is a xylem-limited, plant-pathogenic bacterium that causes destructive diseases in a number of economically important crops, such as Pierce's disease in grapevines, citrus variegated chlorosis in citrus, and bacterial leaf scorch in coffee, plum, and almond (Hopkins and Purcell 2002). In recent years, emergence of $X$. fastidiosa diseases has been reported in new host plants and geographic locations (Chang et al. 2009; Martelli et al. 2016; Su et al. 2013), with the host range expanding to 359 plant species in 75 botanical families (European Food

Nucleotide sequence data is available in the GenBank database under accession numbers KY616728 to KY616749.

Corresponding author: L. De La Fuente; E-mail: 1zd0005@auburn.edu; Telephone: +1.334.844.2582; Fax: +1.334.844.1947.

*The $\boldsymbol{e}$-Xtra logo stands for "electronic extra" and indicates that two supplementary figures and four supplementary tables are published online.

@ 2017 The American Phytopathological Society
Safety Authority 2016). Taxonomically, X. fastidiosa strains worldwide were classified under a single species, but recently, another species was described for Taiwanese strains causing pear leaf scorch (Su et al. 2016). Studies based on multilocus sequence typing and analysis (MLST/MLSA) have proposed five subspecies within $X$. fastidiosa (Nunney et al. 2014a; Scally et al. 2005), i.e., subsp. fastidiosa, sandyi, morus, multiplex, and pauca. The disease mechanism, although not fully understood, involves formation of biofilm in the xylem vessels of host plants and obstruction of xylem sap transport leading to alteration of water and mineral nutrients in aerial plant parts (Chatterjee et al. 2008; De La Fuente et al. 2013). X. fastidiosa strains are vectortransmitted by xylem sap-feeding insects such as sharpshooters and spittlebugs (Redak et al. 2004). There is no known specificity involved in recognition of insect vectors and $X$. fastidiosa subspecies, as a single insect vector was able to transmit multiple subspecies (Almeida and Nunney 2015). However, host plant specificity has been described between and within subspecies (Almeida and Purcell 2003; Almeida et al. 2008; Harris and Balci 2015; Oliver et al. 2014, 2015). Subspecies were believed to be geographically separated, but dissemination of plant materials and insect vectors has led to coexistence of two or more subspecies in the same geographic location (Chen et al. 2005; Nunney et al. 2010, 2014b; Parker et al. 2012).

Despite differences in plant host range, little genetic diversity has been described between $X$. fastidiosa strains that infect different host plants on a genome-wide scale. For example, the grapevine strain Temecula and the citrus strain 9a5c, the most divergent genomes within X. fastidiosa, shared $98 \%$ of their genes and $96 \%$ average amino acid identity when their whole genomes were compared (Van Sluys et al. 2003). However, with the application of MLST/MLSA techniques in $X$. fastidiosa phylogenetics, genetic differences have been described among and within subspecies (Almeida et al. 2008; Nunney et al. 2010, 2014a and c; Scally et al. 2005; Yuan et al. 2010). For instance, strains collected from a single host and geographic location formed different haplotypes when they were analyzed by MLSA of environmentally mediated genes (Parker et al. 2012). Interestingly, studies that detected genetic diversity among $X$. fastidiosa strains have also reported the presence of homologous recombination (HR) (Almeida et al. 2008; Coletta-Filho et al. 2017; Marcelletti and Scortichini 2016; Nunney et al. 2010, 2012; 2013, 2014a and c; Scally et al. 2005). In fact, HR was predicted to have a greater effect in creating genetic diversity in $X$. fastidiosa than point mutation (Kung et al. 2013; 
Scally et al. 2005). Moreover, studies based on genetic data have shown occurrence of intersubspecific HR (IHR) between $X$. fastidiosa subspecies (Nunes et al. 2003) and have hypothesized that IHR leads to plant host shift (Nunney et al. 2012, 2014a and c). Coexistence of different $X$. fastidiosa subspecies has enabled the possibility of IHR to a greater extent. Interestingly, natural competence was described in $X$. fastidiosa (Kung and Almeida 2011) and provided an explanation for the frequent HR events detected by genetic studies.

Natural competence is a phenomenon that involves uptake of naked DNA fragments from the environment and their incorporation into the bacterial genome by HR (Lorenz and Wackernagel 1994). Described by Griffith (1928), natural competence was proposed as a mechanism of nutrient acquisition under starvation conditions (Seitz and Blokesch 2013a) but has been also implicated in repair of damaged DNA (Dorer et al. 2010) and bacterial genome evolution providing adaptive advantage (Baltrus et al. 2008) and increased virulence (Coupat-Goutaland et al. 2011) to the recipient bacterium. In the majority of naturally competent bacteria, competence development is regulated and induced by external environmental cues (Seitz and Blokesch 2013a). Regulatory mechanisms involved in the induction of natural competence have been described in well-studied bacterial systems such as Vibrio cholerae (Antonova and Hammer 2015) and Haemophilus influenzae (Cameron et al. 2008).

However, very limited information exists regarding natural competence in $X$. fastidiosa, as only a few studies have been performed (Kandel et al. 2016; Kung and Almeida 2011, 2014; Kung et al. 2013). Studies so far have demonstrated natural competence of $X$. fastidiosa in vitro in batch cultures (Kandel et al. 2016; Kung and Almeida 2011), solid media (Kandel et al. 2016; Kung and Almeida 2014), and in microfluidic chambers (MC), a system designed to closely resemble the bacterium's natural habitat (Kandel et al. 2016). Natural competence occurred at a high frequency under flow conditions in MC, including conditions with grapevine sap as growth medium (Kandel et al. 2016). Cells developed competence when entering into the exponential growth phase (Kung and Almeida 2011, 2014), appeared to prefer DNA from self sources over foreign sources (Kung and Almeida 2011), and required flanking region homology for recombination (Kung et al. 2013). One key knowledge gap is related to the variability of natural competence among strains, as previous studies were based on a few closely related strains belonging to the same subsp., namely, fastidiosa (Kandel et al. 2016; Kung and Almeida 2011, 2014; Kung et al. 2013). Since both genotypic and phenotypic differences have been described in X. fastidiosa strains (Antonova and Hammer 2015; Coletta-Filho et al. 2017; Oliver et al. 2014, 2015; Parker et al. 2012; Scally et al. 2005), their natural competence abilities could differ, as is the case reported in other naturally competent bacteria (Bossé et al. 2009; Coupat et al. 2008; Evans and Rozen 2013; Fujise et al. 2004; Gromkova et al. 1998; Maughan and Redfield 2009; Sikorski et al. 2002). Moreover, although IHR has been detected by MLST studies and was hypothesized to lead to plant host shift (Nunney et al. 2012; 2014a and 2014c), there is still no experimental evidence demonstrating the generation of recombinants by mixing two different subspecies. Therefore, the objectives of this study were i) to determine the relative ability of natural competence in $X$. fastidiosa strains that belong to different subspecies and ii) to test experimentally if IHR occurs between the two subspecies prevalent in the United States. Results showed that 11 of the 13 strains were naturally competent and recombination occurred at various regions of the genome. One highly virulent strain showed very high recombination with DNA from dead cells and plasmids tested as donors. Moreover, IHR was confirmed between subsp. fastidiosa and subsp. multiplex when combinations of donor and recipients from two subspecies were cocultured. These findings demonstrate that $X$. fastidiosa isolates have different recombination potential, and coexistence of subspecies allows IHR that leads to generation of novel genotypes, which, based on the genomic regions of recombination, could show altered adaptation or virulence.

\section{RESULTS}

\section{X. fastidiosa strains differed in their ability to undergo natural competence.}

Thirteen $X$. fastidiosa strains belonging to two subspecies were tested for natural competence, using plasmids containing an antibiotic-resistant marker flanked on either side by $X$. fastidiosa homologous genomic regions. Natural competence was confirmed in 11 of the 13 strains tested, with recombination frequency ranging from below detection limit to 0.024 per recipient cell (Table 1). Two strains (BBI64 and Georgia Plum) did not recombine with any of the plasmids tested (Table 1). Generally, subspecies fastidiosa strains had higher recombination frequency compared with subspecies multiplex strains, although differences were not significant between the two groups. On comparing flanking DNA sequence homology of the recombination site, strains showed 94 to $100 \%$ identity with the homologous region of the donor plasmid (Supplementary Fig. S1; Supplementary Table S2). Strains belonging to different subspecies had more divergence in the flanking region DNA sequences than the strains within the same subspecies. Although no correlation was detected between recombination frequency and flanking region DNA similarity (pKLN61 $[r=0.39, P=0.33]$ and pAX1.Cm $[r=$ $0.44, P=0.27])$ due to strains within a subspecies having identical flanking DNA regions in most of the cases, for a given strain (e.g., strain Temecula1 with pMSRA-Km plasmid), recombination frequency was reduced when homology was low. However, strains that belonged to the same subspecies and had an identical flanking region differed by orders of magnitude in recombination frequency (Table 1). Strain WM1-1, in particular, achieved highest recombination frequency with all the plasmids tested. Recombination occurred in approximately $2 \%$ of the cells when pKLN61 and pMSRA-Km plasmids were used as donor with WM1-1. Generally, recombination frequency was higher with pKLN61 plasmids than with other plasmids (Table 1).

\section{Recombination frequency was associated to growth rate and twitching motility.}

Recombination frequencies of strains were analyzed for their association with biological parameters such as growth rate, twitching motility, biofilm formation, and cell-to-cell attachment (measured by settling rate). Growth curves (Fig. 1A) were generated by culturing the strains in 96-well plates for 8 days and measuring optical density at $600 \mathrm{~nm}\left(\mathrm{OD}_{600}\right)$. By plotting natural $\log$ of $\mathrm{OD}_{600}$ values against time of growth, strains were estimated to attain exponential growth during 1 to 4 days postinoculation, from which growth rates were calculated (Fig. 1B). Growth curves and growth rate values showed that strains have different growth characteristics. Although growth rates and recombination frequencies were significantly correlated for both plasmids tested with all strains (pKLN61 $[r=0.61, P=$ $0.026]$ and pAX1.Cm $[r=0.65, P=0.015])$, strains having the lowest growth rates (AlmaEM3, BB08-1, BH Elm) were competent, while those having average growth rates (BBI64 and Georgia Plum) were not. Strains differed significantly in other parameters, such as biofilm formation (Fig. 1C), settling rate (Fig. 1D), and twitching motility (Fig. 2A and B). 
Recombination frequency was correlated only with twitching motility (pKLN61 $[r=0.59, P=0.034]$ and pAX1.Cm $[r=0.71$, $P=0.006])$ and not with biofilm (pKLN61 $[r=0.00, P=0.99]$ and pAX1.Cm $[r=0.05, P=0.87])$ or settling rate (pKLN61 $[r=$ $-0.27, P=0.36]$ and pAX1.Cm $[r=-0.36, P=0.22])$. Strains that lacked natural competence (BBI64, Georgia Plum) were also deficient in twitching motility (Fig. 2A and B). Transmission electron microscopy (TEM) imaging of selected strains differing in natural competence and twitching motility showed dense type IV pili (structure involved in twitching motility) for strain WM11 but no type IV pili was observed for strain BBI64 (Fig. 2C). Twitching motility of subsp. fastidiosa strains (except Fetzer and ConnCreek) was significantly higher than that of subsp. multiplex strains (Fig. 2A and B), while settling rate was higher with subsp. multiplex strains than with subsp. fastidiosa strains (Fig. 1D).

\section{Insertion was detected in pili genes of noncompetent and nonmotile strains.}

Sequences of genes involved in natural competence and twitching motility of strains tested in this study were retrieved from whole-genome sequences whenever available. All competence and pili genes screened (pilA, pilB, pilM, pilN, pilO, pilQ, recA, comA, and $c o m F$ ) were intact in all strains except BBI64, in which the pilQ gene was found to be mutated. The BBI64 genomic reads, mapped to the reference Temeculal genome, showed an insertion in the pilQ coding region (PD1691), which was further confirmed by sequencing the pilQ fragment (Supplementary Fig. S2). BBI64 sequences at other competence-related regions had identical sequence to at least one other naturally competent and motile strain of subspecies multiplex. This suggested that the insertion at pilQ rendered BBI64 noncompetent and nonmotile. Another strain ( $p g l A^{-}-\mathrm{KmR}$ ) that lacked twitching and competence in a previous study (Kandel et al. 2016) showed an insertion in the pilM (PD1695) coding region, which was also confirmed by further sequencing (data not shown). No frame-shift mutation was observed in the competence-related genes in another noncompetent and nonmotile strain, Georgia Plum (data not shown).

\section{IHR occurred between $X$. fastidiosa subsp. fastidiosa and $X$. fastidiosa subsp. multiplex.}

IHR was confirmed by mixing different combinations of donor and recipient strains from two subspecies of $X$. fastidiosa under various growth conditions. First, different antibiotic resistant donor and recipient strains from two subspecies, fastidiosa and multiplex, were cocultured in $\mathrm{MC}$, and on agar plates with PD3 medium and acquisition of double antibiotic resistance was assessed. Second, marker (kanamycin and green fluorescent protein [GFP])-tagged, heat-killed donor and wildtype live recipient strains from two subspecies were mixed on agar plates of PD3, and acquisition of the marker was assessed. IHR readily occurred between the two subspecies in MC and agar plates with both-live and live-dead combinations of donor and recipient (Fig. 3). From both-live experiments, on coculturing msrA::Km-WM1-1 (subsp. fastidiosa) and NS1::CmAlmaEM3 (subsp. multiplex), $179 \pm 33$ recombinant colonies per $100 \mu \mathrm{l}$ of culture with a frequency of $5.31 \times 10^{-6}$ in $\mathrm{MC}$, and $96 \pm 8$ recombinant colonies per $100 \mu \mathrm{l}$ of culture with a frequency of $1.1 \times 10^{-5}$ on agar plates were obtained (Fig. 3A). With live-dead combinations, strains WM1-1 and Temecula1 (subsp. fastidiosa) readily recombined DNA from heat killed NS1::Km-AlmaEM3 donor (subsp. multiplex) and strain AlmaEM3 (subsp. multiplex) recombined DNA from heatkilled NS1::Km-WM1-1, NS1::Km-EB92-1, and Temecula1GFP (subsp. fastidiosa) (Fig. 3). The number of recombinants varied ( 1 to 412 colonies per $100 \mu \mathrm{l}$ of culture) depending on donor-recipient combinations. Strain EB92-1 did not recombine with DNA from heat-killed donor but could act as donor for strains of both subspecies (Fig. 3). Strain BBI64 was also unable to recombine with heat-killed donor cells. This strain was not used as heat-killed donor, as it could not be tagged with the antibiotic resistance gene due to lack of recombination. Recombination detected with the heat-killed donor cells demonstrates that natural competence is the horizontal gene transfer mechanism involved.

The occurrence of IHR was further confirmed by polymerase chain reaction (PCR), sequencing, and phenotypic assessment. PCR confirmed insertion of the antibiotic-resistant cassette in the recombinant strain (data not shown). Sequence comparison of the flanking regions, in two recombinants each of heat-killed NS1::Km-AlmaEM3 donor and WM1-1 recipient (WM1-1 recombinants 1 and 2) and heat-killed NS1::Km-WM1-1 donor and AlmaEM3 recipient (AlmaEM3 recombinants 1 and 2) together with the donor and recipient strains, detected recombination of the antibiotic cassette region as well as upstream and

Table 1. Recombination frequency of Xylella fastidiosa strains with various donor plasmids

\begin{tabular}{|c|c|c|c|c|c|}
\hline \multirow[b]{3}{*}{ X. fastidiosa strains } & \multirow[b]{3}{*}{ Subspecies/host plant } & \multicolumn{4}{|c|}{ Recombination frequency $\left[(\text { mean } \pm \mathrm{SE}) \times 10^{-5}\right]^{\mathrm{x}}$} \\
\hline & & \multicolumn{4}{|c|}{ Donor plasmid $\mathbf{y}^{\mathbf{y}}$} \\
\hline & & $\mathbf{p A X} \mathbf{1 .} \mathbf{C m}^{\mathbf{z}}$ & pKLN61 & pMOPB-Km & pMSRA-Km \\
\hline WM1-1 & fastidiosa/grape & $117 \pm 23.54 \mathrm{a}$ & $2,400 \pm 1,200 \mathrm{a}$ & $414.7 \pm 196.1 \mathrm{a}$ & $1,170 \pm 540.1 \mathrm{a}$ \\
\hline Temecula1 & fastidiosa/grape & $14.83 \pm 6.83 b$ & $47.58 \pm 22.85 \mathrm{abcd}$ & $0.60 \pm 0.19 b$ & $0.03 \pm 0.02 b$ \\
\hline Temecula $1 *$ & fastidiosa/grape & $10.91 \pm 2.53 b$ & $21.54 \pm 8.67 \mathrm{bcd}$ & NA & NA \\
\hline CCPM1 & fastidiosa/grape & $19.25 \pm 2.61 \mathrm{ab}$ & $165 \pm 62.82 \mathrm{abc}$ & NA & NA \\
\hline Chard1 & fastidiosa/grape & $18.66 \pm 2.73 \mathrm{ab}$ & $50.94 \pm 16.80 \mathrm{abc}$ & NA & NA \\
\hline Fetzer & fastidiosa/grape & $0.83 \pm 0.15 \mathrm{bcd}$ & $11.93 \pm 2.85 \mathrm{bcd}$ & NA & NA \\
\hline ConnCreek & fastidiosa/grape & $0.17 \pm 0.05 \mathrm{~cd}$ & $8.24 \pm 2.29 \mathrm{bcd}$ & NA & NA \\
\hline EB92-1 & fastidiosa/elderberry & $0.017 \pm 0.01 \mathrm{~d}$ & $7.32 \pm 4.27 \mathrm{~cd}$ & $0.002 \pm 0.001 \mathrm{c}$ & $0.21 \pm 0.21 b$ \\
\hline AlmaEM3 & multiplex/blueberry & $0.085 \pm 0.03 \mathrm{~cd}$ & $7.48 \pm 1.13 \mathrm{bcd}$ & $0.01 \pm 0.006 \mathrm{bc}$ & $0.07 \pm 0.04 \mathrm{~b}$ \\
\hline BB08-1 & multiplex/blueberry & $1.87 \pm 0.59 b c$ & $3.627 \pm 1.16 \mathrm{~d}$ & NA & NA \\
\hline BH Elm & multiplex/Elm & $0.27 \pm 0.18 \mathrm{bcd}$ & $12.25 \pm 6.22 \mathrm{bcd}$ & NA & NA \\
\hline Georgia Plum & multiplex/plum & 0 & 0 & NA & NA \\
\hline BBI64 & multiplex/blueberry & 0 & 0 & 0 & 0 \\
\hline
\end{tabular}


downstream flanking regions (Fig. 4, Supplementary Table S4). The recombinant of AlmaEM3 with heat-killed Temecula1-GFP donor was kanamycin resistant and exhibited green fluorescence (characteristic of donor) and fast precipitation (characteristic of recipient), further confirming occurrence of IHR at the kanamycin/ GFP region (Fig. 5).

\section{Randomly selected intersubspecific recombinants}

did not exhibit alterations in virulence phenotypes.

Randomly selected recombinants generated by intersubspecific recombination on mixing whole genomic DNA of heat-killed NS1::Km-AlmaEM3 donor and WM1-1 recipient (WM1-1 recombinants) and heat-killed NS1::Km-WM1-1 donor and AlmaEM3 recipient (AlmaEM3 recombinants) were assessed for virulence phenotypes by measuring their settling rate and twitching motility in vitro and plant virulence. The recombinants and parameters for their assessment were selected based on the differences observed in their parent strains
(Figs. 1D, 2A and B, and 6A and B). On analyzing the results, the phenotype of recombinants was found to be like that of the recipient parent. WM1-1 recombinants had similar settling rates $\left(0.0023 \pm 0.0007 \mathrm{OD} \mathrm{min}^{-1}, n=4\right)$ and twitching motility $(177 \pm 20.31 \mu \mathrm{m}, n=10)$ to that of WM1-1 (Figs. 1D and 2A and $\mathrm{B}$ ), and AlmaEM3 recombinants had similar settling rates $\left(0.04 \pm 0.002 \mathrm{OD} \mathrm{min}^{-1}, n=5\right)$ and twitching motility $(40 \pm$ $4.5 \mu \mathrm{m}, n=10$ ) to that of AlmaEm3 (Figs. 1D and 2A and B). Virulence scores from in planta disease assessment were also not significantly different between the recombinants and recipient parent. Both recipients (WM1-1 and AlmaEM3) and their recombinants colonized and produced characteristic symptoms of leaf scorch, yellowing, and wilting in tobacco (Fig. 6C). Area under disease progress curve (AUDPC) values in tobacco, derived from the incidence rate, were higher for WM1-1 than for AlmaEM3 but not significantly different between the recipient strain and respective recombinants (Fig. 6A) In blueberry, AlmaEM3 and AlmaEM3 recombinant had
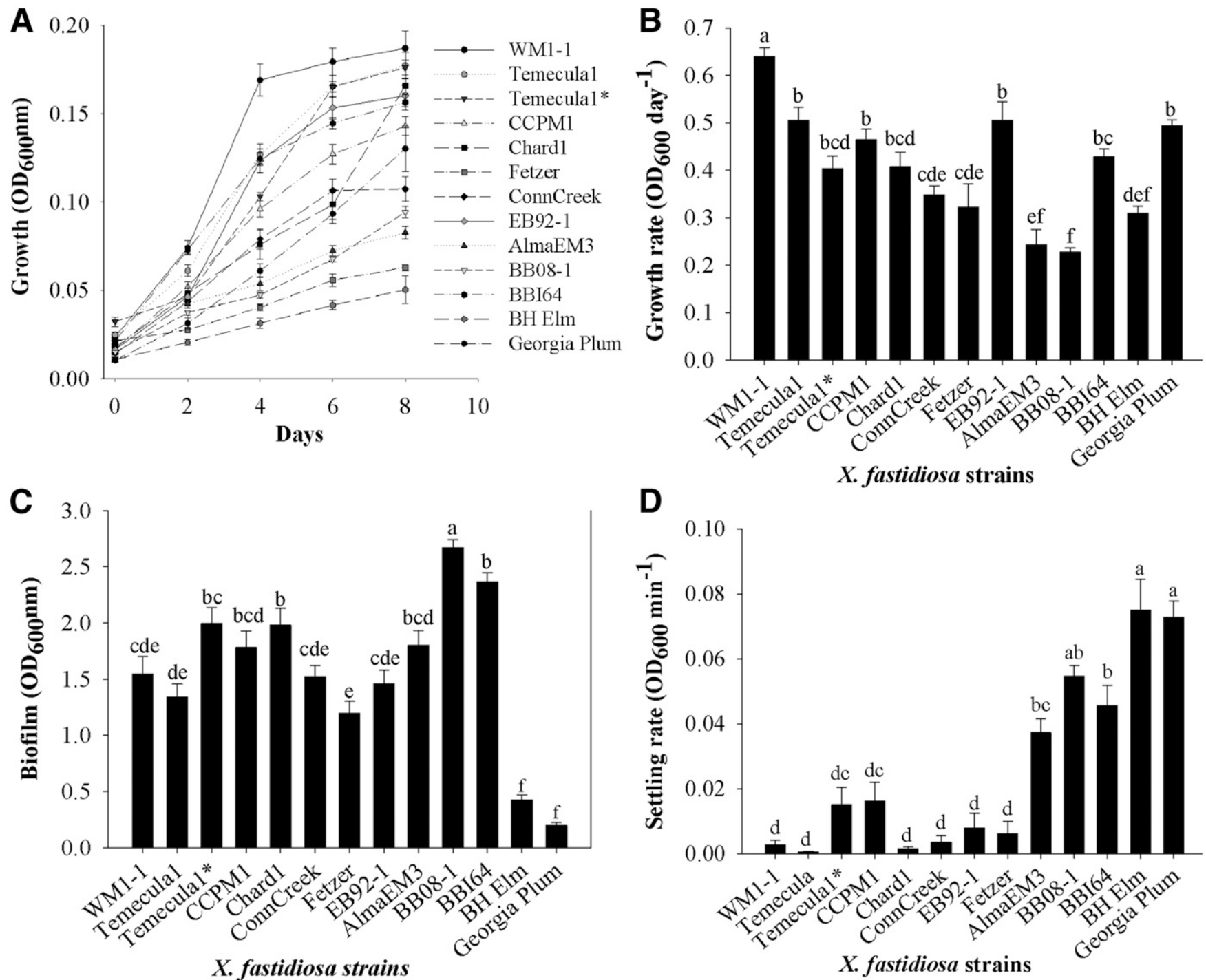

Fig. 1. Growth curves, growth rates, biofilm formation, and settling rates of Xylella fastidiosa strains used in this study. A, Growth curves were generated by culturing the bacteria in 96-well plates and measuring optical density at $600 \mathrm{~nm}\left(\mathrm{OD}_{600}\right)$ values each day for 8 days. B, Growth rate was calculated from the growth curve at the exponential growth phase (1 to 4 days). C, Biofilm was measured, using crystal violet in the 96 -well plates, at the end of the growth-curve experiment. D, Settling rate was measured by suspending the bacteria in a cuvette in $1 \mathrm{ml}$ of PD3 and measuring OD 600 values at 5 -min intervals for 30 min. Each data point indicates mean value from at least three independent experiments. Error bars indicate standard errors. Different letters on top of column bars indicate significant difference as analyzed in SAS 9.3 with PROC GLIMMIX. Post hoc analysis was performed with the Tukey honestly significant difference test at 5\% significance level. 
significantly higher AUDPC values, derived from the weekly disease severity ratings compared with WM1-1 and its recombinant (Fig. 6B). Symptoms such as leaf yellowing, leaf reddening, leaf scorch, match stick, and leaf drop were observed with the plants inoculated with AlmaEM3 and its recombinant only (Fig. 6C). Isolation results confirmed infection by both parent strains and recombinants in tobacco but by only AlmaEM3 and its recombinant in blueberry. Bufferinoculated plants were free of X. fastidiosa in both tobacco and blueberry (data not shown).

\section{Intersubspecific recombination occurred in short and random fragments.}

Length of recombined region was estimated by further sequencing the flanking region of the kanamycin gene insertion site in four of the WM1-1 and AlmaEM3 recombinants previously mentioned (including WM1-1 recombinant 2 and AlmaEM3 recombinant 2, which were used for in planta disease assessment). Length of the recombined region in a single recombination event ranged from 739 to $3,486 \mathrm{bp}$, with recombination extending randomly in the up- and downstream flanking regions. Two independent recombination events separated by an approximately $1-\mathrm{kb}$ region were detected in WM1-1 recombinant 2. Possible recombination that could have occurred at other genomic positions in these recombinants was not assessed.

\section{DISCUSSION}

Previous studies on natural competence in X. fastidiosa were based on a few strains from a single subspecies ( $X$. fastidiosa subsp. fastidiosa), although recombination among strains of other subspecies has been described (Coletta-Filho et al. 2017; Nunes et al. 2003; Nunney et al. 2012; 2013; 2014a and c). On testing natural competence in 13 different strains, almost ubiquitous natural competence ability was detected. The frequency of recombination varied among strains, even for a single genomic region (i.e., same donor plasmid), as in other naturally competent bacteria (Bossé et al. 2009; Coupat et al. 2008; Evans and Rozen 2013; Fujise et al. 2004). Flanking region DNA similarity of the strains was not correlated with the recombination frequency, but most of the strains within a subspecies had identical flanking regions. A clearer understanding on the rate of recombination and homology between recombining DNA could have been obtained by using donor DNA containing a different level of similarity with the recipient strain at a given recombination region. However, this was not
A
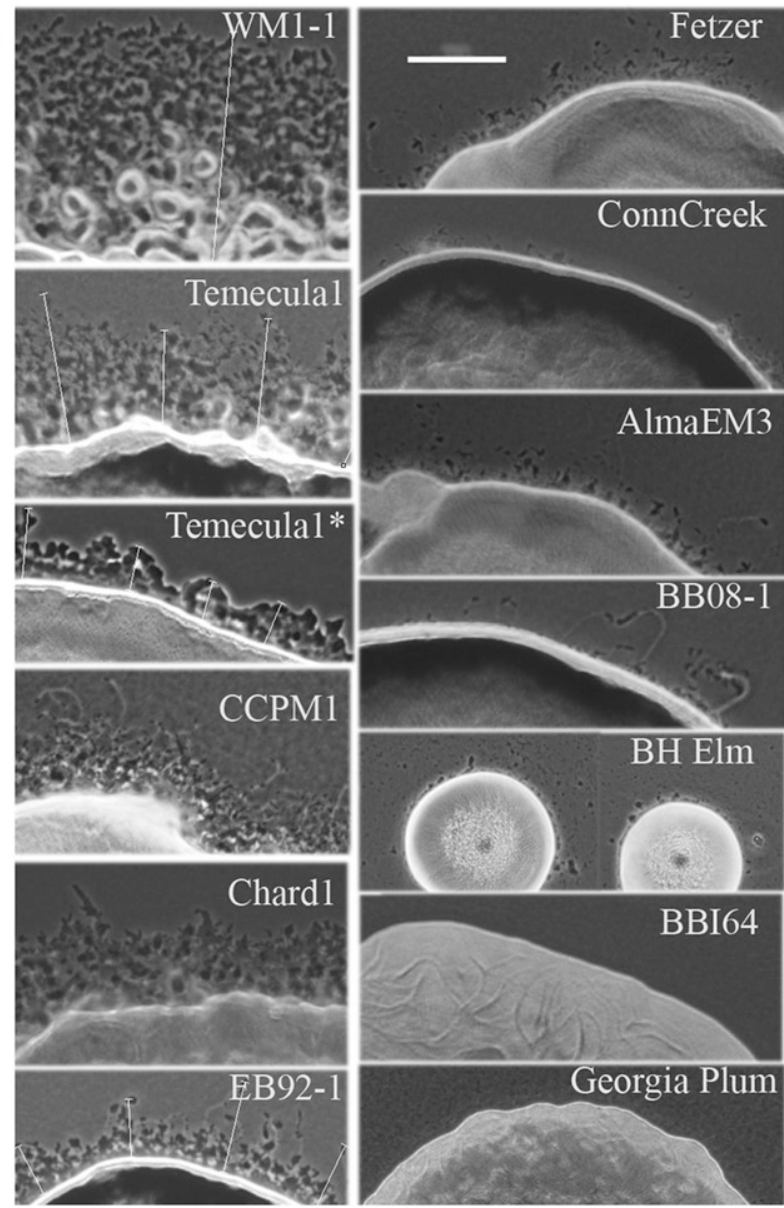
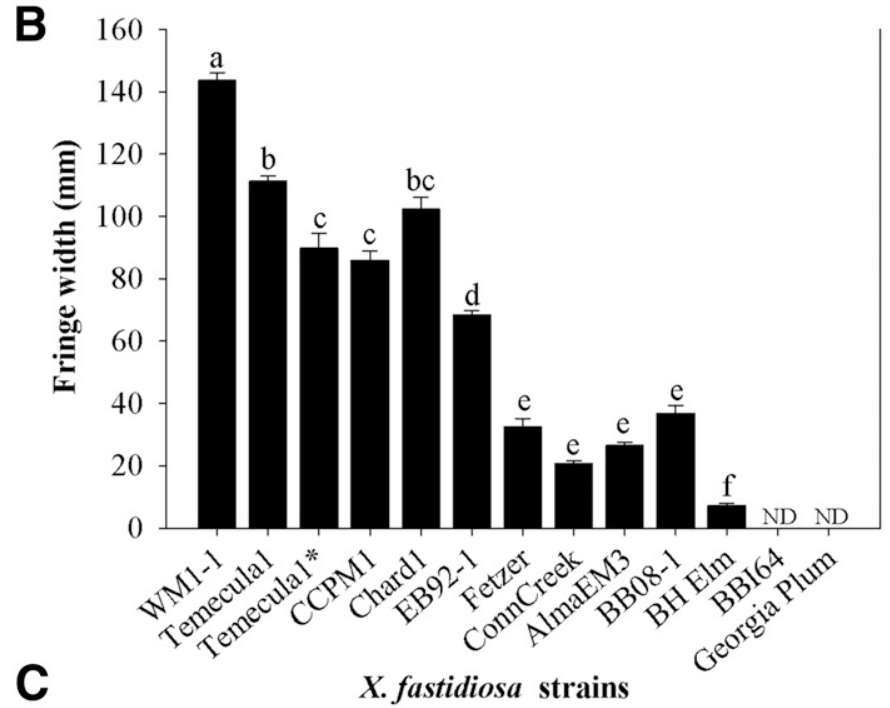

\section{X. fastidiosa strains}

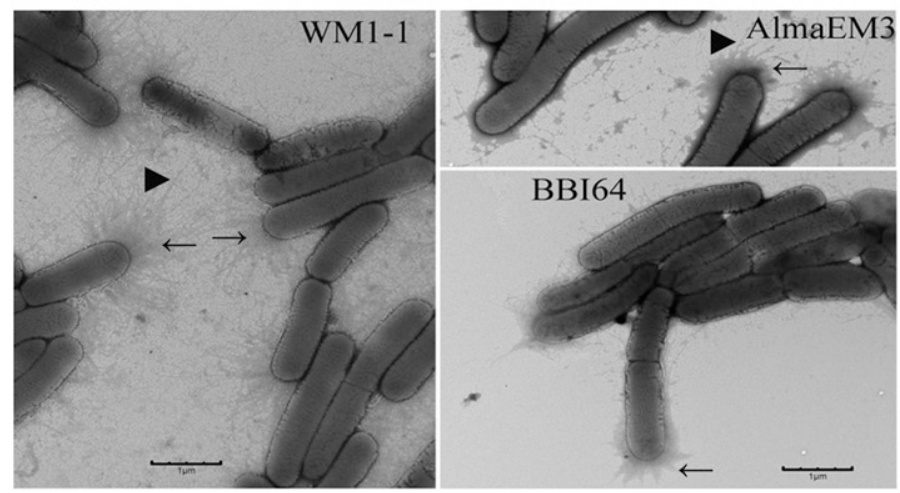

Fig. 2. Twitching motility of Xylella fastidiosa strains used in this study. A, Twitching motility was assessed by measuring the fringe width of the bacterial colonies spotted on PD3 plates after 3 to 5 days of incubation. The horizontal white bar on the top right panel indicates $100 \mu$ m. Measurements included at least three biological replicates with four technical replicates per time, except for BH Elm, for which motility was measured only once with three technical replicates. B, Twitching motility differed among strains, as analyzed in SAS 9.3 with PROC GLIMMIX. Post hoc analysis was performed with a Tukey honestly significant difference test at $5 \%$ significance level. Different letters on top of bars represent significant difference in twitching motility. Error bars indicate standard error for independent replicates. ND: motility was not detected. C, Transmission electron microscopy images of selected strains. Strain WM1-1 and AlmaEM3 exhibited dense pili, both long (type IV pili indicated by a solid black arrowhead) and short (type I pili indicated by left and right arrows), while no long pili were observed for BBI64. Scale bar indicates $1 \mu \mathrm{m}$, magnification $125,000 \times$. 
performed in this study. Even if differences in recombination frequency, especially between strains of different subspecies, could be due to differences in homology between donor and recipient DNA sequences or differences in growth rates that showed positive correlation with recombination frequency, these parameters did not explain the noncompetency of two strains that had average growth and similar sequence homology compared with the competent strains. Also, since growth of the strains was measured by OD and strains appeared to differ in the rate of cell-to-cell attachment, growth values could have been biased, especially for the strains that showed high rates of precipitation (due to stronger cell-to-cell attachment). This was not further investigated, as it was beyond the scope of this study.
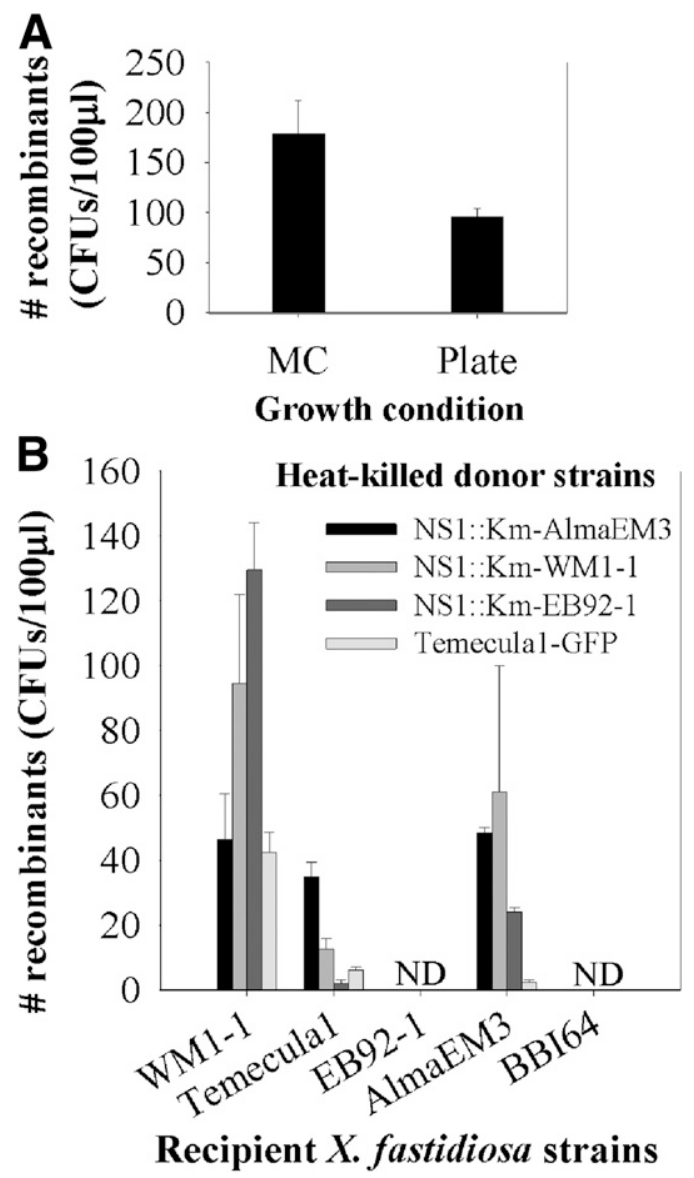

Fig. 3. Intra- and intersubspecific recombination in Xylella fastidiosa. A, Recombination between antibiotic resistance marker-tagged $X$. fastidiosa strains belonging to subspecies fastidiosa (msrA::Km-WM1-1) and subspecies multiplex (NS1::Cm-AlmaEM3) when cultured together in microfluidic chamber (MC) and agar plates with PD3. Double antibiotic-resistant recombinant colonies were recovered from both settings. B, Recombination of $X$. fastidiosa strains with heat-killed donor cells. Donor strains were tagged with a kanamycin-resistant marker at the neutral (NS1) site using pAX1.Km plasmids, except for the Temecula1-GFP strain, and were heatkilled by incubating at $90^{\circ} \mathrm{C}$ for $15 \mathrm{~min}$. Heat-killed donor and recipient strains were mixed on spots of PD3 agar plates and were incubated at $28^{\circ} \mathrm{C}$ for 3 to 4 days. Recombinants were selected by plating the mixed spots in $\mathrm{PW}-\mathrm{Km}$ agar plates. Intersubspecific recombination was confirmed by mixing heat-killed strains of subspecies fastidiosa (NS1::Km -WM1-1, Temecula1-GFP, and NS1::Km-EB92-1) with a recipient of subspecies multiplex (AlmaEM3) and heat-killed NS1::Km-AlmaEM3 with recipients of subspecies fastidiosa. Bars represent the mean number of recombinants obtained for each combination of recipient and donor. Experiments were repeated at least three times with three replicates each. ND indicates recombinants were not detected for these strains when used as recipients.
On further testing of other biological traits, twitching motility was significantly correlated with recombination frequency. Strain WM1-1 had the highest recombination frequency and showed highest motility among strains, while the two noncompetent strains were nonmotile. Positive correlation between recombination frequency and twitching motility was also suggested in our previous study using different media components (Kandel et al. 2016). Since components of type IV pili are involved in both natural competence and twitching motility in several naturally competent gram-negative bacteria (Seitz and Blokesch 2013a), including X. fastidiosa (Kung and Almeida 2014), the activity of type IV pili could govern both of these phenomena. On further analysis of competence and pili genes, defective pili genes were detected in the noncompetent strains. One of the defective proteins detected was PilQ (strain BBI64), a member of the secretin family that forms the secretin pore of the outer membrane (Collins et al. 2001) and is involved in type IV pili biogenesis and importing extracellular DNA into the periplasmic space (Seitz and Blokesch 2013b). Previous studies in X. fastidiosa have demonstrated that pilQ mutants are nonmotile (Meng et al. 2005) and noncompetent (Kung and Almeida 2014). Hence, we predict that the insertion in the pilQ coding region is responsible for the lack of twitching and natural competence, as BBI64 is unable to secrete the type IV pili. The lack of type IV pili was confirmed by TEM imaging. Motility has been described as a major virulence trait for $X$. fastidiosa (De La Fuente et al. 2007; Meng et al. 2005). BBI64 has no motility and WM1-1 has the highest motility in this study. Consistent with the critical role of twitching in virulence, BBI64 had reduced virulence while WM1-1 was highly virulent (Oliver et al. 2014, 2015). A further observation supporting the correlation between twitching and natural competence was the fact that the Fetzer strain showed recombination in this study, while a mutant in the polygalacturonase gene $\mathrm{pglA}$ of this strain did not (Kandel et al. 2016). On closer examination, Fetzer is motile (this study) while the pglA mutant is not (Kandel et al. 2016). Sequence data showed that the pglA mutant had an insertion in pilM, a type IV pili biogenesis gene that was shown to be involved in twitching motility of Acidovorax avenae in a previous study (Bahar et al. 2009), most probably causing the lack of movement in this strain.

Additional factors could be involved in causing differences in natural competence of $X$. fastidiosa strains. X. fastidiosa genomes contain high levels of phage and phage-like regions (de Mello Varani et al. 2008; Nunes et al. 2003; Van Sluys et al. 2003), and natural competence could be a mechanism to help cells eliminate new integration of these regions by recombining the homologous DNA without phage sequences, as suggested by a recent study (Croucher et al. 2016). Other studies have reported restriction-modification (R-M) systems limiting transformation frequency (Niza et al. 2016). In this study, although all donor plasmids were extracted from an Escherichia coli strain expressing $X$. fastidiosa DNA methyl transferase (Matsumoto and Igo 2010), it is possible that different strains, especially from different genetic backgrounds, possess different forms of R-M systems, which could lead to differences in the amount of DNA available for recombination, causing differences in recombination frequency. In this regard, a previous study has reported the inability of a plasmid isolated from a citrus-infecting strain to transform a grape strain (Guilhabert and Kirkpatrick 2003), suggesting existence of specific recognition mechanisms to differentiate DNA from self or foreign sources. Sequence analysis and annotation of the $X$. fastidiosa Temecula1 genome predicts at least four different types of R-M systems (Matsumoto and Igo 2010). Future studies focused on these specific topics could explain the differences in recombination frequencies observed among $X$. fastidiosa strains. 
Differences in recombination frequencies based on genomic positions was previously reported in Ralstonia solanacearum (Fall et al. 2007), with positions containing recombination hot spots (recA and mutS) showing the highest frequency (Fall et al. 2007). In this study, higher recombination frequency was observed for pKLN61, a plasmid that recombines in the region of $r p f F$ gene, a diffusible signaling factor involved in cell-to-cell communication of $X$. fastidiosa (Newman et al. 2004), compared with pAX1.Cm, which recombines at a neutral site (Matsumoto et al. 2009), and pMOPB-Km and pMSRA-Km, which recombine at regions whose functions are being characterized. Differences in the length of the homologous flanking region and nonhomologous insert have been found to influence recombination frequency in a previous study (Kung et al. 2013). However, the upstream and downstream flanking region length was higher in pAX1.Cm (759 to $790 \mathrm{bp}$ ), pMOPB-Km (about $800 \mathrm{bp}$ ), and pMSRA-Km (about $800 \mathrm{bp}$ ) than for pKLN61 (about $350 \mathrm{bp}$ at one end and $750 \mathrm{bp}$ at the other end). The length of the nonhomologous insert between the homologous flanking regions was similar (about 1,200 bp) and the size of the plasmids is also comparable (about $5 \mathrm{~kb}$ ). Moreover, flanking region DNA sequence identity between the donor plasmids and recipient strains at these positions was also similar (except for EB92-1 at pAX1.Cm and Temecula1 for pMSRA-Km). This suggests that the difference in recombination frequency at different genomic position is not associated with the characteristics of plasmid regions, and it remains to be determined if this difference holds any evolutionary significance.
Natural competence has been proposed to bring adaptive changes to the recipient bacteria, such as repair of damaged DNA (Dorer et al. 2010) and generation of genetic diversity that can lead to adaptation (Baltrus et al. 2008). For the generation

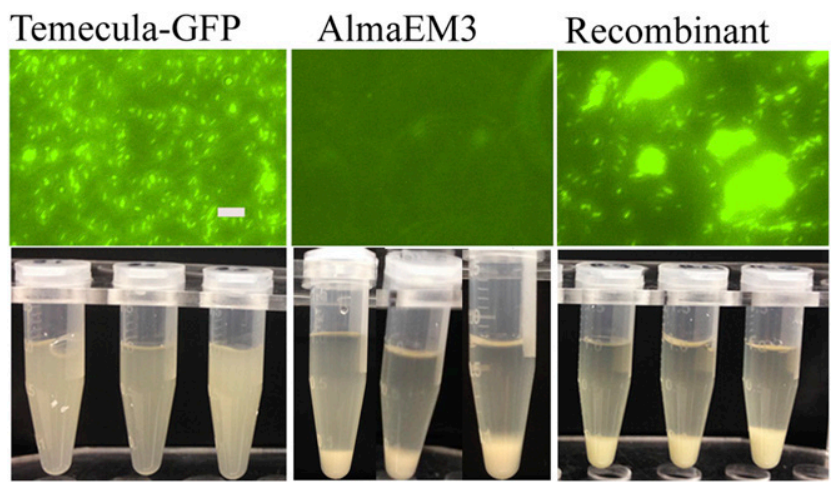

Fig. 5. Confirmation of intersubspecific recombination in Xylella fastidiosa by movement of the green fluorescence gene from the Temecula-GFP donor (subsp. fastidiosa) to the AlmaEM3 recipient (subsp. multiplex). The upper panel shows fluorescence characteristics of donor, recipient, and recombinant, as observed under a fluorescence microscope; and the lower panel shows the precipitation behavior of respective strains after suspending the cells in PD3 and allowing settling for about $1 \mathrm{~h}$. The recombinant showed fluorescence (characteristic of donor) as well as fast settling (characteristic of recipient), confirming that recombination occurred at the GFP locus. Scale bar $=10 \mu \mathrm{m}$.

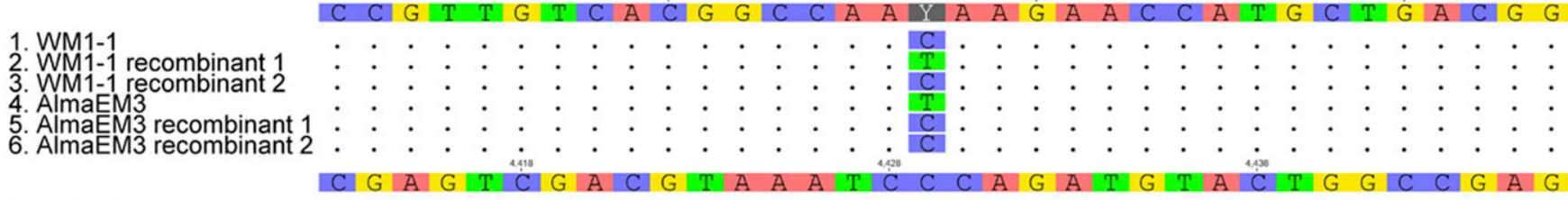

\section{WM1-1 3. WM1-1 recombinant 2 4. AlmaEM3 \\ 5. AlmaEM3 recombinant 1 \\ AlmaEM3 recombinant 2}

1. WM1-1

3. WM1-1 recombinant 2

4. AlmäM3

5. AlmaEM3

6. AlmaEM3 recombinant 1

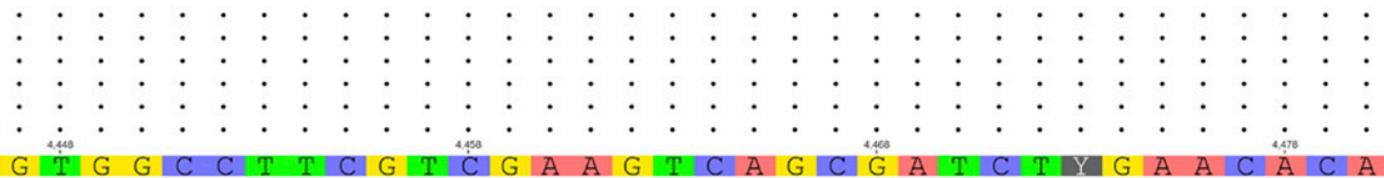

1. WM1-1
2. WM1-1 recombinant 1
3. WM1-1 recombinant 2
4. AlmaEM3
5. AlmaEM3 recombinant
6. AlmaEM3 recombinant
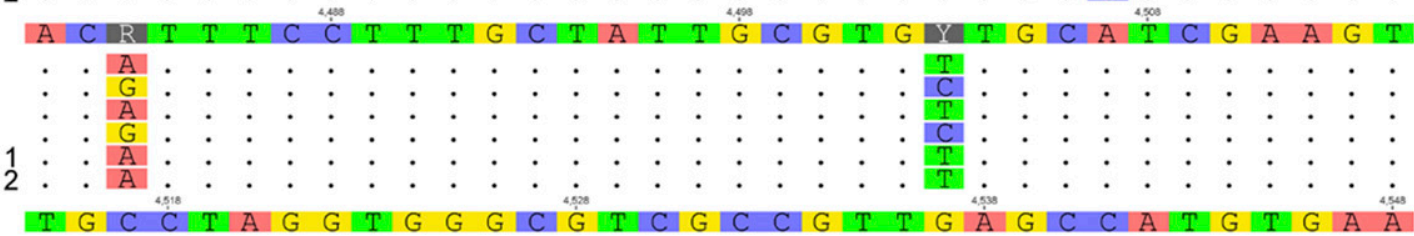

1. WM1-1

2. WM1-1 recombinant 1

4. AlmaEM3

5. AlmaEM3 recombinant

6. AlmaEM3 recombinant 2
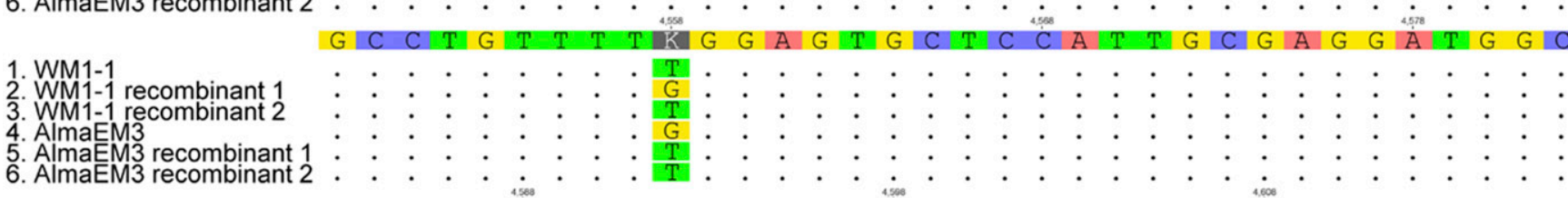

Fig. 4. Confirmation of intersubspecific recombination by sequencing. Multiple sequence alignment of sequences from donor, recipient, and recombinant strains in the upstream and downstream region of antibiotic insertion was performed. WM1-1 and AlmaEM3 are wild-type strains belonging to Xylella fastidiosa subsp. fastidiosa and multiplex, respectively. WM1-1 recombinants were generated by mixing wild-type WM1-1 with heat-killed NS1::KmAlmaEM3, and AlmaEM3 recombinants were generated by mixing wild-type AlmaEM3 with heat-killed NS1::Km-WM1-1. The shown region is 1,037 bp downstream of the kanamycin-resistant gene insertion site and $247 \mathrm{bp}$ downstream of the homologous region used in the construct. Recombination occurred in WM1-1 recombinant 1 and both AlmaEM3 recombinants but not in WM1-1 recombinant 2 at the region shown here. 
of adapted strains, recombining regions should come from a more successful and genetically distinct donor (CoupatGoutaland et al. 2011). This could be possible when closely related but genetically different strains of a same species coexist in a single habitat. Detection of IHR in X. fastidiosa by MLST/MLSA studies (Nunney et al. 2012; 2014a and c) supported this possibility. In fact, these studies proposed IHR leading to plant host shift of $X$. fastidiosa in citrus (Nunney et al. 2012), mulberry (Nunney et al. 2014c), and blueberry (Nunney et al. 2014a). Moreover, mixed infection of the two subspecies have been suggested by previous studies. For example, almond leaf scorch strains isolated from the same orchard were found to be genetically different (Chen et al. 2005, 2010) and were grouped into two different subspecies, i.e., subsp. fastidiosa and multiplex (Yuan et al. 2010). Infection of a plum tree showing leaf scorch symptoms by subsp. multiplex and subsp. pauca strains was also reported in a recent study (Coletta-Filho et al. 2017). Results of this and previous studies (Oliver et al. 2014, 2015) demonstrated that certain plants serve as hosts for strains from multiple subspecies. In addition, vectors of $X$. fastidiosa are found to be distributed worldwide in both temperate and tropical climates and, unlike with plant hosts, exhibit no specificity for pathogen genotype (Almeida et al. 2005). In fact, a species of the vector (Homalodisca vitripennis) was able to transmit four subspecies of $X$. fastidiosa (Almeida and Nunney 2015). All these observations suggest that strains belonging to different subspecies may coexist within the same habitat (plant or insect), providing opportunities for recombination.
Although IHR was detected between subspecies when whole genomes of the donor (heat killed) and recipient were mixed, recombinants did not differ significantly with the parent in virulence phenotypes, suggesting that recombination did not bring phenotypic changes. On analyzing the flanking homologous region of recombination, 0.7 - to 4 -kb regions were detected to have recombined, but the size could be greater, as up to $80 \mathrm{~kb}$ has been demonstrated to recombine by natural competence in $R$. solanacearum, with the recombinant strain showing increased virulence (Coupat-Goutaland et al. 2011). Moreover, recombination could also occur at genomic regions other than the antibiotic insertion site, as the whole genomic DNA was used as donor to generate these recombinants. However, due to the bias of the method used here that selected recombinants acquiring antibiotic resistance, recombination that occurred at other regions in the genome may not have been present in the recombinants selected for assessment in this study. In addition, only the minimum size of recombination events could be estimated based on existing polymorphisms. Nonetheless, by targeting various genomic regions, it was confirmed that recombination occurred at multiple regions. Future studies by optimizing the selection procedures for recombinants in the context of pathogenicity to plants could reveal changes in virulence due to IHR in X. fastidiosa.

Interestingly, IHR was bidirectional, meaning that both subspecies could act as both donor and recipient for one another. The evidence from field observation of $X$. fastidiosa disease emergence in new plant species and the detection of IHR in strains isolated from these infections by MLST/MLSA
A

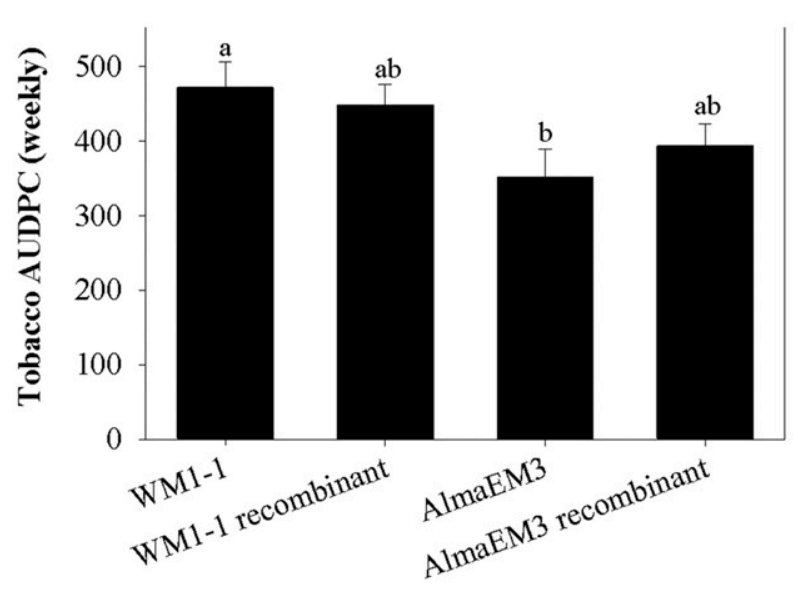

B

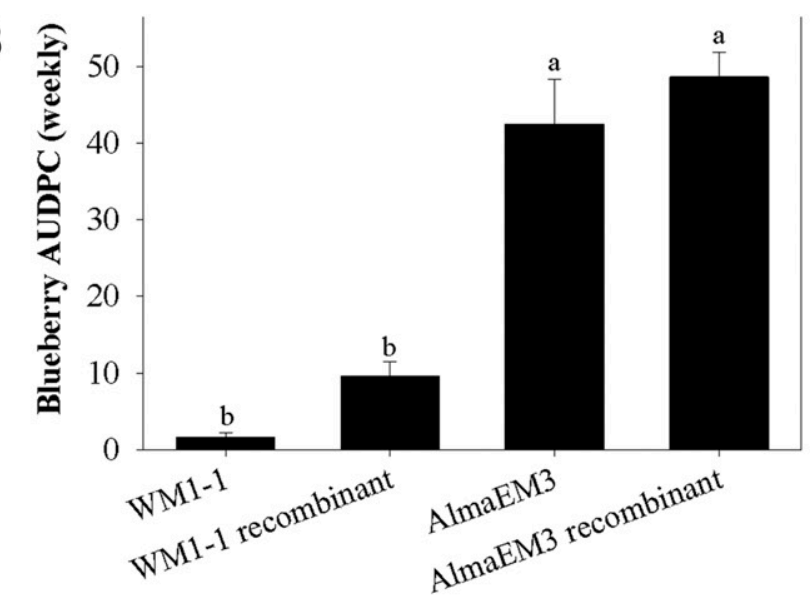

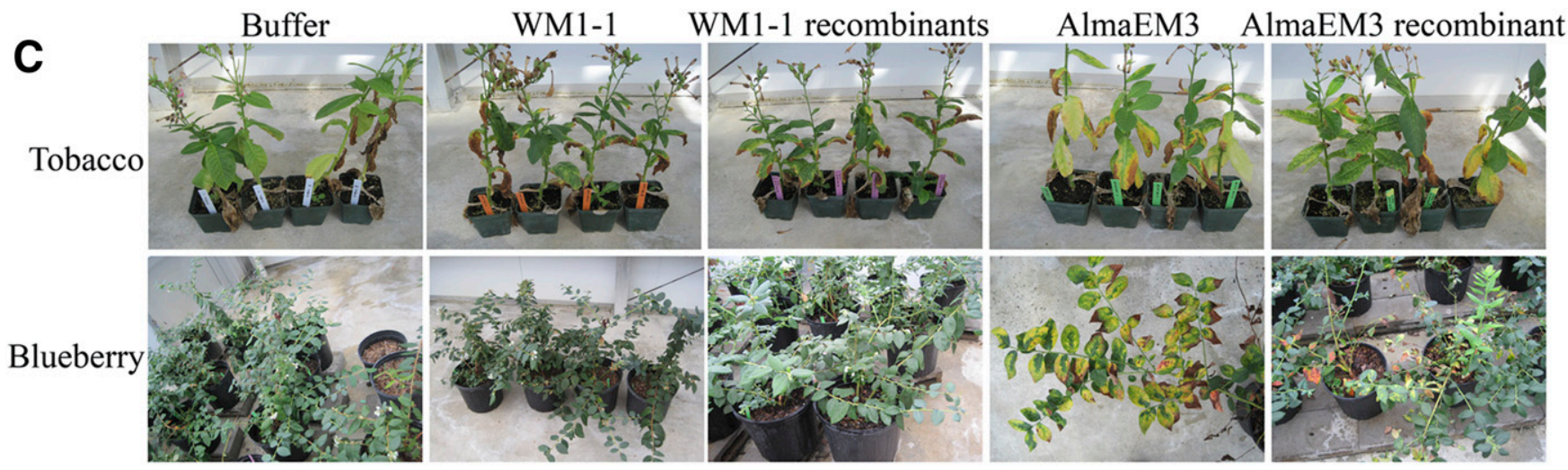

Fig. 6. Virulence test of donor, recipient, and recombinant strains in the greenhouse. Area under disease progress curve (AUDPC) values were different between parents but did not differ between the recipient and the recombinant strains, suggesting that recombination did not change virulence behavior. Tobacco experiments were performed twice with ten plants per treatment (data are shown from a representative experiment), and a blueberry experiment was performed once with ten plants in each treatment. Both WM1-1 and AlmaEM3 and their recombinants produced symptoms in tobacco, while only AlmaEM3 and their recombinants produced symptoms in blueberry. 
(Coletta-Filho et al. 2017) and from confirmation of natural competence in habitats mimicking natural environments (Kandel et al. 2016) to the experimental validation of IHR (this study) suggests that IHR is occurring in nature and may have broader evolutionary implications in $X$. fastidiosa disease dynamics. In conclusion, $X$. fastidiosa strains showed extensive natural competence abilities and the recombination potential differed among strains. Moreover, intersubspecific recombination occurred readily between $X$. fastidiosa subsp. fastidiosa and subsp. multiplex strains. These results emphasize the importance of quarantine measures to limit the introduction of novel genotypes of $X$. fastidiosa in areas with pre-existing infection. Moreover, measures to isolate host plants of different subspecies may be required to prevent mixed infections, minimizing the risk of generating novel and virulent genotypes of $X$. fastidiosa by recombination.

\section{MATERIALS AND METHODS}

\section{Bacterial strains, media, and culture conditions.}

$X$. fastidiosa subsp. fastidiosa strains WM1-1, Temecula1, Temecula1*, CCPM1, Fetzer, ConnCreek, and EB92-1 and subsp. multiplex strains AlmaEM3, BB08-1, BBI64, Birmingham Elm (BH Elm), and Georgia Plum were used in this study. Strain Chard1 was isolated from infected vines of Vitis vinifera 'Chardonnay' in Dahlonega, Georgia in 2014 and is assumed to be a subsp. fastidiosa strain, based on its plant host (Supplementary Table S1). A Temecula1 mutant expressing GFP (Temecula1-GFP) was used from a previous study (Newman et al. 2003). Mutant strains NS1::Km-WM1-1, NS1::KmEB92-1, and NS1::Km-AlmaEM3 were generated by transforming the wild-type strains with pAX1.Km plasmids, and strain NS1::Cm-AlmaEM3 was generated by transforming with pAX1.Cm plasmids (Matsumoto et al. 2009), which insert the respective antibiotic resistant genes at a neutral site (NS1) in the genome. Mutant strain msrA::Km-WM1-1 was generated by transforming pMSRA-Km. All transformations were performed using the natural competence protocol described below.

All strains were cultured for 1 week in PW (Davis et al. 1980) agar plates modified by replacing phenol red with $1.8 \mathrm{~g}$ of bovine serum albumin per liter (Gibco Life Sciences Technology), at $28^{\circ} \mathrm{C}$ from $-80^{\circ} \mathrm{C}$ glycerol stock and were restreaked onto new PW plates and cultured for another week before use. Medium PD3 (Davis et al. 1981) was used to suspend the cells in liquid and for natural competence experiments. Luria Bertani medium was used to culture E. coli cells. Kanamycin, chloramphenicol, and ampicillin were used at a concentration of 30 , 10 , and $100 \mathrm{\mu g} \mathrm{ml}^{-1}$, respectively.

\section{Test of natural competence of $X$. fastidiosa strains.}

Plasmids pAX1.Cm (Matsumoto et al. 2009) and pKLN61 (Newman et al. 2004) were used from previous studies. Plasmids pMSRA-Km and pMOPB-Km were prepared as described earlier (Cruz et al. 2014) and are being characterized for another study in our laboratory (Chen 2016). Briefly, about 800 bp long upstream and downstream fragments flanking open reading frames of methionine S-S-oxide reductase ( $m s r A$; PD0859) and outer membrane protein (mopB, PD1709), respectively, were PCR amplified from the Temeculal genomic DNA. The upstream and downstream fragments were digested using Asci restriction enzyme (Promega), were ligated, and were cloned into pJET1.2/blunt cloning vector, and a kanamycin-resistant cassette was inserted between the two fragments. All the plasmids were transformed into $E$. coli EAM1competent cells that express $X$. fastidiosa DNA methylase (Matsumoto and Igo 2010). Plasmids were prepared from the overnight cultures of EAM1 using an extraction kit (GeneJet plasmid miniprep kit;
Thermo Scientific), and concentration was adjusted to100 $\mathrm{ng} / \mu \mathrm{l}$ (NanoDrop 2000 spectrophotometer; Thermo Scientific). Aliquots were stored at $-20^{\circ} \mathrm{C}$ until use. Natural competence assays were performed in PD3 agar plates. The recipient strains were adjusted to $\mathrm{OD}_{600}$ of 0.25 (approximately $10^{8}$ cells per milliliter) in PD3 broth. Ten microliters of this suspension were spotted onto PD3 agar plates and $1 \mu \mathrm{g}$ of plasmid in a $10-\mu l$ volume was added to the spots. Following incubation at $28^{\circ} \mathrm{C}$ for about 3 days (for noncompetent strains this incubation time was extended up to 5 days), spots were suspended in $1 \mathrm{ml}$ of PD3 and serial dilutions were plated in the respective antibiotic (kanamycin or chloramphenicol) PW plates in triplicates, depending on which antibiotic cassette each plasmid carried, and PW plates without antibiotics. After 2 to 3 weeks of incubation at $28^{\circ} \mathrm{C}$, CFUs were enumerated for recombinants (number of colonies formed on antibiotic-supplemented PW plates) and total viable cells (number of colonies formed on appropriate dilutions of PW plates without antibiotics), followed by calculation of recombination frequency as the ratio of the number of recombinants to total viable cells. For a given experiment, at least three repetitions were performed per strain, and the experiments had two to six biological replicates. For each strain, spots without the addition of plasmids were included as controls for every experiment. Genomic incorporation of the antibiotic-resistant marker from the donor plasmid was confirmed by PCR as previously described (Kandel et al. 2016).

\section{Comparison of the flanking region DNA sequences of donor and recipient strains.}

To compare flanking region DNA sequence homology among recipient $X$. fastidiosa strains with respect to each donor plasmid, up- and downstream flanking regions of the antibiotic insertion sites of plasmids pAX1.Cm, pKLN61, pMSRA-Km, and $\mathrm{pMOPB}-\mathrm{Km}$ were obtained. Up-and downstream sequences homologous to each plasmid region were obtained from the genomes of strains WM1-1, Temecula1, Temecula1*, BB08-1, AlmaEM3, BBI64 (unpublished data), and EB92-1 (Zhang et al. 2011). The genomes (except EB92-1) were sequenced using Illumina Miseq and PacBio sequencing systems, and resulting reads after quality trimming were mapped to the Temecula1 reference genome, using the Geneious map to reference algorithm (Kearse et al. 2012). The two up-and downstream sequences were concatenated, were aligned using the Muscle Multiple Sequence Alignment tool in Geneious, and percent identity between each of the donor plasmids and recipient strains was determined.

\section{Growth curve, biofilm, settling rate, and twitching motility measurements of $X$. fastidiosa strains.}

Growth curves of strains were generated by culturing strains in PD3 medium in 96-well plates and measuring the $\mathrm{OD}_{600}$ value every day for 8 days. At the beginning (day 0), wells of the 96-well plate were inoculated with $190 \mu \mathrm{l}$ of PD3 and $10 \mu \mathrm{l}$ of cell suspension $\left(\mathrm{OD}_{600}=0.25\right)$ with eight wells (repetitions) used per strain. Eight wells were filled with $200 \mu$ l of PD3 to serve as controls. The plates were incubated at $27^{\circ} \mathrm{C}$, with shaking at $150 \mathrm{rpm}$ per minute. $\mathrm{OD}_{600}$ values were measured using Cytation 3 multimode imaging reader (Biotek) and were adjusted by subtracting values from control wells. Growth rates were calculated as the slope of line obtained by natural logtransformed growth values at the exponential growth phase (approximately 1 to 4 days) using the formula $\{$ rate $=[\ln (\mathrm{OD}$ day 4$)-\ln ($ OD day 1$)] /$ time $\}$. Biofilm was quantified using the crystal violet assay, as previously described (Cruz et al. 2012), at the end of the growth curve experiment (day 8). Settling rate, as a measure of cell-to-cell attachment, was determined by measuring $\mathrm{OD}_{600}$ of a cell suspension in a cuvette when cells 
appeared to settle exponentially (5 to 30 min postinoculation [mpi]). Settling rate was calculated as in growth rate, using the formula $\{$ rate $=[\ln (\mathrm{OD} 5 \mathrm{mpi})-\ln (\mathrm{OD} 30 \mathrm{mpi})] /$ time $\}$. Twitching motility measurement was performed as previously described (Kandel et al. 2016). Experiments were repeated independently at least three times with at least three technical replicates per time.

\section{TEM.}

X. fastidiosa strains WM1-1, AlmaEM3, and BBI64 were used with TEM imaging to observe the presence of type IV pilli (structure involved in natural competence and twitching motility). Strains were cultured in PD3 agar plates for 3 days from the second restreak mentioned above. Cells from the edges of the colony were suspended in $100 \mu \mathrm{l}$ of sterile water. Six microliters of this suspension was pipetted on a formvar-carbon coated TEM grid, and cells were allowed to settle for $10 \mathrm{~min}$. The leftover liquid was blotted out with a filter paper. The grid was then negatively stained with $6 \mu$ l of phopshotungistic acid (PTA) for $2 \mathrm{~min}$, and, after removing the excess PTA, grids were air dried and were observed under Zeiss EM10 transmission electron microscopy (Carl Zeiss). Images were acquired with MaxIm DL software (Diffraction LTD).

\section{Sequence comparision of genes \\ of $\boldsymbol{X}$. fastidiosa strains involved in natural competence.}

Sequence comparison of the genes involved in natural competence in $X$. fastidiosa (Kung and Almeida 2014) strains that were positive and negative for natural competence was performed. Sequences of genes (pilA, pilB, pilM, pilQ, pilO, recA, $\operatorname{com} A$, and $\operatorname{com} F$ ) were extracted either from public databases or from reference mapping assembly (discussed above). Sequences were used in a multiple sequence alignment tool in Geneious. Mutations and insertions or deletions were analyzed. Insertions or deletions were further confirmed by Sanger sequencing of both forward and reverse fragments (Eurofin $\mathrm{Ge}$ nomics), using specific primers (Supplementary Table S3). Primers were designed with the Primer3 primer design tool in Geneious, and PCR was performed with standard protocol using the iProof High-Fidelity PCR kit (BioRad). PCR products were purified using PCR extract mini kit (5 PRIME) before sequencing.

\section{Test of intra-HR and IHR.}

To assess IHR, X. fastidiosa strains belonging to subsp. fastidiosa and subsp. multiplex were used. In one set of experiments, subsp. fastidiosa WM1-1 was tagged with a kanamycinresistant marker at the $m s r A$ genomic region ( $m s r A:: \mathrm{Km}-\mathrm{WM} 1-1)$ and subsp. multiplex strain AlmaEM3 was tagged with a chloramphenicol-resistant marker at the NS1 site (NS1::CmAlmaEM3) using the natural competence protocol described above. These two mutant strains were cocultured in MC for 5 days and on solid agar plates for 3 days with PD3 medium, as previously described (Kandel et al. 2016). Double antibioticresistant recombinants were selected by plating the mixed culture in PW agar medium supplemented with both kanamycin and chloramphenicol. Experiments were performed once in the MC and three times with three replicates each time in the plate setting. Single strain spots were used as controls in the plates.

In another set of experiments, antibiotic/GFP marker-tagged donor strains were heat-killed by incubating a suspension $\left(\mathrm{OD}_{600}\right.$ of approximately 0.8 ) at $90^{\circ} \mathrm{C}$ for $15 \mathrm{~min}$. Heat-killed donor strains were spotted on PD3 plates on top of live recipient strains. NS1::Km-WM1-1, NS1::Km-EB92-1, and Temecula1GFP from subsp. fastidiosa and NS1::Km-AlmaEM3 from subsp. multiplex were used as donor strains, while WM1-1, Temecula1, and EB92-1 (fastidiosa) and AlmaEM3, and BBI64 (multiplex) were used as recipient strains. The donors and recipients were mixed as in the plasmid recombination protocol described above. Experiments were repeated at least three times with three replications each time for WM1-1 and AlmaEM3 combinations. Recipient-only spots were included as controls. The complete killing of donor strains was confirmed by plating aliquots of $100 \mu \mathrm{l}$ in PW plates.

\section{Confirmation of intersubspecific recombination.}

To confirm that the recombinants received the antibiotic/GFP marker from the donor strain, PCR and sequencing approaches were performed. PCR confirmation was done as previously described (Kandel et al. 2016). Up- and downstream flanking regions and the antibiotic region of two selected recombinants of heat-killed NS1::Km-AlmaEM3 and WM1-1 (WM1-1 recombinant 1 and 2) and heat-killed NS1::Km-WM1-1 and AlmaEM3 (AlmaEM3 recombinant 1 and 2) were sequenced using Sanger sequencing platform, as mentioned above, using specific primers. Primers were designed with Primer3 primer design tool in Geneious, and PCR was performed with standard protocol using iProof High-Fidelity PCR kit (BioRad). PCR products were purified using PCR extract mini kit (5 PRIME) before sequencing. Resulting sequences were concatenated and were aligned in a multiple sequence alignment, together with the donor and recipient sequences, to confirm the movement of antibiotic, upstream, and downstream region from the donor to the recipient. Selected recombinants of heat-killed Temecula-GFP donor and AlmaEM3 recipient were confirmed by both observing GFP fluorescence, using a Nikon Eclipse Ti inverted microscope (Nikon), and precipitation tests in Eppendorf tubes.

\section{Virulence assessment in vitro and in planta.}

The recipient parent strains WM1-1, and AlmaEM3 and randomly selected recombinants of the two strains were tested in vitro for twitching motility and settling, as the parents differed in these two traits. Twitching motility and settling measurement was performed as described above. Virulence test of the parents and randomly selected recombinants (WM1-1 recombinant 2 and AlmaEM3 recombinant 2) was performed in the greenhouse at the Plant Science Research Center, Auburn University, in a completely randomized design. The parent strains and their recombinants were inoculated in model plant tobacco (Nicotiana tabaccum) cultivar SR1 'Petite Havana', and host blueberry (Vaccinium 'Rebel' [PPA18, 138]). Disease incidence and disease severity ratings on a scale of 0 to 7 for tobacco and blueberries, respectively, were recorded as previously described (Oliver et al. 2014, 2015). Briefly, for tobacco, symptomatic and total leaves were counted, and percent incidence was calculated for each plant as [(symptomatic leaves/ total leaves) $\times 100$ ]. Symptom rating was performed weekly for four to six times after the appearance of first symptoms (about 60 days postinoculation). For blueberry, severity scores (0 to 7) were given to each of the two stems of each plant and the average score of the two stems was calculated. AUDPC was calculated for each plant based on the weekly values of incidence rate for tobacco and average severity scores for blueberry. AUDPC values were calculated based on the midpoint rule method (Campbell and Madden 1990): AUDPC $=\sum \mathrm{i}^{n-1}\left[\left(y_{\mathrm{i}}+y_{\mathrm{i}+1}\right) / 2\right]$ $\left(t_{\mathrm{i}+1}-t_{\mathrm{i}}\right)$, where $n=$ number of times disease assessment was performed, $y=$ score of incidence or severity for each plant, and $t=$ time of assessment. Tobacco experiments were performed twice with 10 plants per treatment and the blueberry experiment was performed once with 10 plants per treatment. Following disease scoring, selected plants were used to isolate the bacteria from the petiole/midrib region of the leaves of plants inoculated with $X$. fastidiosa and buffer control as described in a previous study (Parker et al. 2012). 


\section{Sequence accession numbers.}

Nucleotide sequences of genes of natural competence, flanking regions, and recombinant sequences were deposited in the National Center for Biotechnology Information GenBank database under accession numbers KY616728 to KY616749.

\section{Statistical analysis.}

Recombination frequencies of the strains were log-transformed and were analyzed using PROC GLIMMIX in SAS 9.3, followed by posthoc analysis using TUKEY-HSD (honest significant difference) at $P \leq 0.05$. Treatments or replicates that had zero frequency values were excluded from the analysis. Virulence traits (fringe width, settling rate, biofilm, AUDPC values) were also compared in SAS 9.3 with PROC GLIMMIX and TUKEY-HSD at $P \leq 0.05$. Correlation analysis among the variables was carried out in R 3.2.5, with cor.test and rcorr functions under Hmisc package (Ihaka and Gentleman 1996).

\section{ACKNOWLEDGMENTS}

This project was funded by the HATCH AAES (Alabama Agricultural Experiment Station) program and Agriculture and Food Research Initiative competitive grant number 2015-67014-23085 from the United States Department of Agriculture National Institute of Food and Agriculture. We thank M. E. Miller, director of the AU Research and Instrumentation Facility, for his help with TEM, S. Lindow (University of California Berkeley) for providing a GFP-marked strain, J. Parker for her help with Miseq library preparation and genome sequencing, A. Retchless and D. Stenger for sharing unpublished genome data, and $\mathrm{L}$. Cruz for providing $m o p B$ and $m s r A$ mutant constructs.

\section{LITERATURE CITED}

Almeida, R. P., Blua, M. J., Lopes, J. R., and Purcell, A. H. 2005. Vector transmission of Xylella fastidiosa: Applying fundamental knowledge to generate disease management strategies. Ann. Entomol. Soc. Am. 98: 775-786.

Almeida, R. P. P., Nascimento, F. E., Chau, J., Prado, S. S., Tsai, C. W., Lopes, S. A., and Lopes, J. R. S. 2008. Genetic structure and biology of Xylella fastidiosa strains causing disease in citrus and coffee in Brazil. Appl. Environ. Microbiol. 74:3690-3701.

Almeida, R. P. P., and Nunney, L. 2015. How do plant diseases caused by Xylella fastidiosa emerge? Plant Dis. 99:1457-1467.

Almeida, R. P. P., and Purcell, A. H. 2003. Transmission of Xylella fastidiosa to grapevines by Homalodisca coagulata (Hemiptera: Cicadellidae). J. Econ. Entomol. 96:264-271.

Antonova, E. S., and Hammer, B. K. 2015. Genetics of natural competence in Vibrio cholerae and other vibrios. Microbiol. Spectr. 3. doi:10.1128/ microbiolspec.VE-0010-2014. Published online.

Bahar, O., Goffer, T., and Burdman, S. 2009. Type IV Pili are required for virulence, twitching motility, and biofilm formation of acidovorax avenae subsp. Citrulli. Mol. Plant-Microbe Interact 22:909-920.

Baltrus, D. A., Guillemin, K., and Phillips, P. C. 2008. Natural transformation increases the rate of adaptation in the human pathogen Helicobacter pylori. Evolution 62:39-49.

Bossé, J. T., Sinha, S., Schippers, T., Kroll, J. S., Redfield, R. J., and Langford, P. R. 2009. Natural competence in strains of Actinobacillus pleuropneumoniae. FEMS Microbiol. Lett. 298:124-130.

Cameron, A. D. S., Volar, M., Bannister, L. A., and Redfield, R. J. 2008. RNA secondary structure regulates the translation of sxy and competence development in Haemophilus influenzae. Nucleic Acids Res. 36:10-20.

Campbell, C. L., and Madden, L. V. 1990. Introduction to Plant Disease Epidemiology. John Wiley \& Sons, New York.

Chang, C. J., Donaldson, R., Brannen, P., Krewer, G., and Boland, R. 2009. Bacterial leaf scorch, a new blueberry disease caused by Xylella fastidiosa. HortScience 44:413-417.

Chatterjee, S., Almeida, R. P., and Lindow, S. 2008. Living in two worlds: The plant and insect lifestyles of Xylella fastidiosa. Annu. Rev. Phytopathol. 46:243-271.

Chen, H. 2016. Effect of calcium on biofilm development and role of mopB and $m s r A$ in virulence of Xylella fastidiosa. Master's thesis. Auburn University, Auburn, AL, U.S.A.

Chen, J., Groves, R., Civerolo, E. L., Viveros, M., Freeman, M., and Zheng, Y. 2005. Two Xylella fastidiosa genotypes associated with Almond Leaf
Scorch disease on the same location in California. Phytopathology 95 708-714.

Chen, J., Xie, G., Han, S., Chertkov, O., Sims, D., and Civerolo, E. L. 2010. Whole genome sequences of two Xylella fastidiosa strains (M12 and M23) causing almond leaf scorch disease in California. J. Bacteriol. 192: 4534.

Coletta-Filho, H. D., Francisco, C. S., Lopes, J. R., Muller, C., and Almeida, R. P. 2017. Homologous recombination and Xylella fastidiosa hostpathogen associations in South America. Phytopathology 107:305-312.

Collins, R. F., Davidsen, L., Derrick, J. P., Ford, R. C., and Tønjum, T. 2001 Analysis of the PilQ secretin from Neisseria meningitidis by transmission electron microscopy reveals a dodecameric quaternary structure. J. Bacteriol. 183:3825-3832.

Coupat, B., Chaumeille-Dole, F., Fall, S., Prior, P., Simonet, P., Nesme, X., and Bertolla, F. 2008. Natural transformation in the Ralstonia solanacearum species complex: Number and size of DNA that can be transferred. FEMS Microbiol. Ecol. 66:14-24.

Coupat-Goutaland, B., Bernillon, D., Guidot, A., Prior, P., Nesme, X., and Bertolla, F. 2011. Ralstonia solanacearum virulence increased following large interstrain gene transfers by natural transformation. Mol. PlantMicrobe Interact 24:497-505.

Croucher, N. J., Mostowy, R., Wymant, C., Turner, P., Bentley, S. D., and Fraser, C. 2016. Horizontal DNA transfer mechanisms of bacteria as weapons of intragenomic conflict. PLoS Biol. 14:e1002394.

Cruz, L. F., Cobine, P. A., and De La Fuente, L. 2012. Calcium increases Xylella fastidiosa surface attachment, biofilm formation, and twitching motility. Appl. Environ. Microbiol. 78:1321-1331.

Cruz, L. F., Parker, J. K., Cobine, P. A., and De La Fuente, L. 2014. Calcium-enhanced twitching motility in Xylella fastidiosa is linked to a single pily1 homolog. Appl. Environ. Microbiol. 80:7176-7185.

Davis, M., French, W., and Schaad, N. 1981. Axenic culture of the bacteria associated with phony disease of peach and plum leaf scald. Curr. Microbiol. 6:309-314.

Davis, M. J., Purcell, A. H., and Thomson, S. V. 1980. Isolation media for the Pierce's disease bacterium. Phytopathology 70:425-429.

De La Fuente, L., Burr, T. J., and Hoch, H. C. 2007. Mutations in type I and type IV pilus biosynthetic genes affect twitching motility rates in Xylella fastidiosa. J. Bacteriol. 189:7507-7510.

De La Fuente, L., Parker, J. K., Oliver, J. E., Granger, S., Brannen, P. M., van Santen, E., and Cobine, P. A. 2013. The bacterial pathogen Xylella fastidiosa affects the leaf ionome of plant hosts during infection. PLoS One 8:e62945

de Mello Varani, A., Souza, R. C., Nakaya, H. I., de Lima, W. C., Paula de Almeida, L. G., Kitajima, E. W., Chen, J., Civerolo, E., Vasconcelos, A. T., and Van Sluys, M. A. 2008. Origins of the Xylella fastidiosa prophage-like regions and their impact in genome differentiation. PLoS One 3:e4059.

Dorer, M. S., Fero, J., and Salama, N. R. 2010. DNA damage triggers genetic exchange in Helicobacter pylori. PLoS Pathog. 6:e1001026.

European Food Safety Authority. 2016. Update of a database of host plants of Xylella fastidiosa: November 20, 2015. EFSA J. 14:4378.

Evans, B. A., and Rozen, D. E. 2013. Significant variation in transformation frequency in Streptococcus pneumoniae. ISME J. 7:791-799.

Fall, S., Mercier, A., Bertolla, F., Calteau, A., Gueguen, L., Perrière, G. Vogel, T. M., and Simonet, P. 2007. Horizontal gene transfer regulation in bacteria as a "spandrel" of DNA repair mechanisms. PLoS One 2: e1055.

Fujise, O., Lakio, L., Wang, Y., Asikainen, S., and Chen, C. 2004. Clonal distribution of natural competence in Actinobacillus actinomycetemcomitans. Oral Microbiol. Immunol. 19:340-342.

Griffith, F. 1928. The significance of pneumococcal types. J. Hyg. (Lond.) 27:113-159.

Gromkova, R. C., Mottalini, T. C., and Dove, M. G. 1998. Genetic transformation in Haemophilus parainfluenzae clinical isolates. Curr. Microbiol. 37:123-126.

Guilhabert, M. R., and Kirkpatrick, B. C. 2003. Transformation of Xylella fastidiosa with broad host range RSF1010 derivative plasmids. Mol Plant Pathol. 4:279-285.

Harris, J. L., and Balci, Y. 2015. Population structure of the bacterial pathogen Xylella fastidiosa among street trees in Washington D.C. PLoS One 10:e121297.

Hopkins, D. L., and Purcell, A. H. 2002. Xylella fastidiosa: Cause of Pierce's disease of grapevine and other emergent diseases. Plant Dis. 86: 1056-1066.

Ihaka, R., and Gentleman, R. 1996. R: A language for data analysis and graphics. J. Comput. Graph. Stat. 5:299-314.

Kandel, P. P., Lopez, S. M., Almeida, R. P., and De La Fuente, L. 2016. Natural competence of Xylella fastidiosa occurs at a high frequency 
inside microfluidic chambers mimicking the bacterium's natural habitats. Appl. Environ. Microbiol. 82:5269-5277.

Kearse, M., Moir, R., Wilson, A., Stones-Havas, S., Cheung, M., Sturrock, S., Buxton, S., Cooper, A., Markowitz, S., Duran, C., Thierer, T., Ashton, B., Meintjes, P., and Drummond, A. 2012. Geneious Basic: An integrated and extendable desktop software platform for the organization and analysis of sequence data. Bioinformatics 28:1647-1649.

Kung, S. H., and Almeida, R. P. 2011. Natural competence and recombination in the plant pathogen Xylella fastidiosa. Appl. Environ. Microbiol. 77: 5278-5284.

Kung, S. H., and Almeida, R. P. 2014. Biological and genetic factors regulating natural competence in a bacterial plant pathogen. Microbiology 160:37-46

Kung, S. H., Retchless, A. C., Kwan, J. Y., and Almeida, R. P. 2013. Effects of DNA size on transformation and recombination efficiencies in Xylella fastidiosa. Appl. Environ. Microbiol. 79:1712-1717.

Lorenz, M. G., and Wackernagel, W. 1994. Bacterial gene transfer by natural genetic transformation in the environment. Microbiol. Rev. 58: 563-602.

Marcelletti, S., and Scortichini, M. 2016. Genome-wide comparison and taxonomic relatedness of multiple Xylella fastidiosa strains reveal the occurrence of three subspecies and a new Xylella species. Arch. Microbiol. 198:803-812.

Martelli, G. P., Boscia, D., Porcelli, F., and Saponari, M. 2016. The olive quick decline syndrome in south-east Italy: A threatening phytosanitary emergency. Eur. J. Plant Pathol. 144:235-243.

Matsumoto, A., and Igo, M. M. 2010. Species-specific type II restrictionmodification system of Xylella fastidiosa temecula1. Appl. Environ. Microbiol. 76:4092-4095.

Matsumoto, A., Young, G. M., and Igo, M. M. 2009. Chromosome-based genetic complementation system for Xylella fastidiosa. Appl. Environ. Microbiol. 75:1679-1687.

Maughan, H., and Redfield, R. J. 2009. Extensive variation in natural competence in Haemophilus influenzae. Evolution 63:1852-1866.

Meng, Y., Li, Y., Galvani, C. D., Hao, G., Turner, J. N., Burr, T. J., and Hoch, H. C. 2005. Upstream migration of Xylella fastidiosa via pilusdriven twitching motility. J. Bacteriol. 187:5560-5567.

Newman, K. L., Almeida, R. P. P., Purcell, A. H., and Lindow, S. E. 2003. Use of a green fluorescent strain for analysis of Xylella fastidiosa colonization of Vitis vinifera. Appl. Environ. Microbiol. 69:7319-7327.

Newman, K. L., Almeida, R. P. P., Purcell, A. H., and Lindow, S. E. 2004. Cell-cell signaling controls Xylella fastidiosa interactions with both insects and plants. Proc. Natl. Acad. Sci. U.S.A. 101:1737-1742.

Niza, B., Merfa, M. V., Alencar, V. C., Menegidio, F. B., Nunes, L. R., Machado, M. A., Takita, M. A., and de Souza, A. A. 2016. Draft genome sequence of 11399, a transformable citrus-pathogenic strain of Xylella fastidiosa. Genome Announc. 4:e01124-16.

Nunes, L. R., Rosato, Y. B., Muto, N. H., Yanai, G. M., da Silva, V. S., Leite, D. B., Gonçalves, E. R., de Souza, A. A., Coletta-Filho, H. D., Machado, M. A., Lopes, S. A., and de Oliveira, R. C. 2003. Microarray analyses of Xylella fastidiosa provide evidence of coordinated transcription control of laterally transferred elements. Genome Res. 13:570-578.

Nunney, L., Hopkins, D. L., Morano, L. D., Russell, S. E., and Stouthamer, R. 2014a. Intersubspecific recombination in Xylella fastidiosa Strains native to the United States: Infection of novel hosts associated with an unsuccessful invasion. Appl. Environ. Microbiol. 80:1159-1169.

Nunney, L., Ortiz, B., Russell, S. A., Ruiz Sánchez, R., and Stouthamer, R. 2014b. The complex biogeography of the plant pathogen Xylella fastidiosa: Genetic evidence of introductions and Subspecific introgression in Central America. PLoS One 9:e112463.

Nunney, L., Schuenzel, E. L., Scally, M., Bromley, R. E., and Stouthamer, R. 2014c. Large-scale intersubspecific recombination in the plantpathogenic bacterium Xylella fastidiosa is associated with the host shift to mulberry. Appl. Environ. Microbiol. 80:3025-3033.

Nunney, L., Vickerman, D. B., Bromley, R. E., Russell, S. A., Hartman, J. R., Morano, L. D., and Stouthamer, R. 2013. Recent evolutionary radiation and host plant specialization in the Xylella fastidiosa subspecies native to the United States. Appl. Environ. Microbiol. 79: 2189-2200
Nunney, L., Yuan, X., Bromley, R., Hartung, J., Montero-Astúa, M., Moreira, L., Ortiz, B., and Stouthamer, R. 2010. Population genomic analysis of a bacterial plant pathogen: Novel insight into the origin of Pierce's disease of grapevine in the U.S. PLoS One 5:e15488.

Nunney, L., Yuan, X., Bromley, R. E., and Stouthamer, R. 2012. Detecting genetic introgression: High levels of intersubspecific recombination found in Xylella fastidiosa in Brazil. Appl. Environ. Microbiol. 78: 4702-4714.

Oliver, J. E., Cobine, P. A., and De La Fuente, L. 2015. Xylella fastidiosa isolates from both subsp. multiplex and fastidiosa cause disease on southern highbush blueberry (Vaccinium sp.) under greenhouse conditions. Phytopathology 105:855-862.

Oliver, J. E., Sefick, S. A., Parker, J. K., Arnold, T., Cobine, P. A., and De La Fuente, L. 2014. Ionome changes in Xylella fastidiosa-infected Nicotiana tabacum correlate with virulence and discriminate between subspecies of bacterial isolates. Mol. Plant-Microbe Interact 27: 1048-1058.

Parker, J. K., Havird, J. C., and De La Fuente, L. 2012. Differentiation of Xylella fastidiosa strains via multilocus sequence analysis of environmentally mediated genes (MLSA-E). Appl. Environ. Microbiol. 78: 1385-1396.

Redak, R. A., Purcell, A. H., Lopes, J. R. S., Blua, M. J., Mizell, R. F., 3rd, and Andersen, P. C. 2004. The biology of xylem fluid-feeding insect vectors of Xylella fastidiosa and their relation to disease epidemiology. Annu. Rev. Entomol. 49:243-270.

Scally, M., Schuenzel, E. L., Stouthamer, R., and Nunney, L. 2005. Multilocus sequence type system for the plant pathogen Xylella fastidiosa and relative contributions of recombination and point mutation to clonal diversity. Appl. Environ. Microbiol. 71:8491-8499.

Seitz, P., and Blokesch, M. 2013a. Cues and regulatory pathways involved in natural competence and transformation in pathogenic and environmental Gram-negative bacteria. FEMS Microbiol. Rev. 37:336-363.

Seitz, P., and Blokesch, M. 2013b. DNA-uptake machinery of naturally competent Vibrio cholerae. Proc. Natl. Acad. Sci. U.S.A. 110:17987 17992.

Sikorski, J., Teschner, N., and Wackernagel, W. 2002. Highly different levels of natural transformation are associated with genomic subgroups within a local population of Pseudomonas stutzeri from soil. Appl. Environ. Microbiol. 68:865-873.

Su, C. C., Chang, C. J., Chang, C. M., Shih, H. T., Tzeng, K. C., Jan, F. J., Kao, C. W., and Deng, W. L. 2013. Pierce's disease of grapevines in Taiwan: Isolation, cultivation and pathogenicity of Xylella fastidiosa. J. Phytopathol. 161:389-396.

Su, C. C., Deng, W. L., Jan, F. J., Chang, C. J., Huang, H., Shih, H. T., and Chen, J. 2016. Xylella taiwanensis sp. nov., causing pear leaf scorch disease. Int. J. Syst. Evol. Microbiol. 66:4766-4771.

Van Sluys, M. A., de Oliveira, M. C., Monteiro-Vitorello, C. B., Miyaki, C. Y., Furlan, L. R., Camargo, L. E., da Silva, A. C., Moon, D. H., Takita, M. A., Lemos, E. G., Machado, M. A., Ferro, M. I., da Silva, F. R., Goldman, M. H., Goldman, G. H., Lemos, M. V., El-Dorry, H., Tsai, S. M., Carrer, H., Carraro, D. M., de Oliveira, R. C., Nunes, L. R., Siqueira, W. J., Coutinho, L. L., Kimura, E. T., Ferro, E. S., Harakava, R., Kuramae, E. E., Marino, C. L., Giglioti, E., Abreu, I. L., Alves, L. M., do Amaral, A. M., Baia, G. S., Blanco, S. R., Brito, M. S., Cannavan, F. S., Celestino, A. V., da Cunha, A. F., Fenille, R. C., Ferro, J. A., Formighieri, E. F., Kishi, L. T., Leoni, S. G., Oliveira, A. R., Rosa, V. E., Jr., Sassaki, F. T., Sena, J. A., de Souza, A. A., Truffi, D., Tsukumo, F., Yanai, G. M., Zaros, L. G., Civerolo, E. L., Simpson, A. J., Almeida, N. F., Jr., Setubal, J. C., and Kitajima, J. P. 2003. Comparative analyses of the complete genome sequences of Pierce's disease and citrus variegated chlorosis strains of Xylella fastidiosa. J. Bacteriol. 185:1018-1026.

Yuan, X., Morano, L., Bromley, R., Spring-Pearson, S., Stouthamer, R., and Nunney, L. 2010. Multilocus sequence typing of Xylella fastidiosa causing Pierce's disease and oleander leaf scorch in the United States. Phytopathology 100:601-611.

Zhang, S., Flores-Cruz, Z., Kumar, D., Chakrabarty, P., Hopkins, D. L., and Gabriel, D. W. 2011. The Xylella fastidiosa biocontrol strain EB92-1 genome is very similar and syntenic to Pierce's disease strains. J. Bacteriol. 193:5576-5577. 